\title{
An interaction between PAC1 receptor and serotonin 2A receptor involved in receptor trafficking and signal transduction
}

\author{
Yusuke Shintani $^{1}$, Atsuko Hayata-Takano ${ }^{1,2}$, Naoki Encho ${ }^{1}$, Keita Moriguchi $^{1}$, Hitoshi Hashimoto ${ }^{1,2,3}$ \\ ${ }^{1}$ Laboratory of Molecular Neuropharmacology, Graduate School of Pharmaceutical Sciences, Osaka University, Japan, \\ ${ }^{2}$ United Graduate School of Child Development, Osaka University, Osaka, Japan, ${ }^{3}$ Institute for Datability Science, \\ Osaka University, Osaka, Japan
}

[Objective] PACAP (pituitary adenylate cyclase-activating polypeptide) is a multifunctional neuropeptide that regulates a wide array of physiological responses, including, e.g. emotion, cognition and motor function. We previously demonstrated that PACAP-deficient mice display remarkable psychomotor disturbances, most of which were ameliorated with the atypical antipsychotic risperidone and the selective serotonin $2 \mathrm{~A}$ receptor $\left(5-\mathrm{HT}_{2 \mathrm{~A}} \mathrm{R}\right)$ antagonist ritanserin. These findings suggest a possible alteration of $5-\mathrm{HT}_{2 \mathrm{~A}} \mathrm{R}$ signaling in PACAP-deficient mice and a functional interaction between PACAP and $5-\mathrm{HT}_{2 \mathrm{~A}} \mathrm{R}$-mediated 5 - $\mathrm{HT}$ signaling. However, the underlying mechanisms remain unclear. Recent studies have demonstrated that some GPCRs can form heterodimers, potentially influencing pharmacological signaling pathways and receptor internalization. Here, we therefore investigated the relationship between PACAP-specific receptor (PAC1R) and $5-\mathrm{HT}_{2 \mathrm{~A}} \mathrm{R}$ using the NanoBiT protein and protein interaction assay system.

[Methods] To detect membrane surface and total cellular levels of $5-\mathrm{HT}_{2 \mathrm{~A}} \mathrm{R}$ and PAC1R, we performed subcellular fractionation followed by western blotting analysis in brain lysates in wild type and PACAP-deficient mice. The NanoBiT assays were conducted in HEK293T cells transfected with NanoBiT-fused $5-\mathrm{HT}_{2 \mathrm{~A}} \mathrm{R}$ and PAC1R and subjected to luminescence measurements.

[Results] We observed that the surface levels of $5-\mathrm{HT}_{2 \mathrm{~A}} \mathrm{R}$ and PAC1R significantly increased in PACAP-deficient mice, but the total cellular levels of $5-\mathrm{HT}_{2 \mathrm{~A}} \mathrm{R}$ were not different. The NanoBiT assay detected a weak but long-lasting luminescence which is considered to show the $5-\mathrm{HT}_{2 \mathrm{~A}} \mathrm{R}$ and PAC1R interaction.

[Conclusions] The present results suggest that $5-\mathrm{HT}_{2 \mathrm{~A}} \mathrm{R}$ and PAC1R mutually interact and this interaction is, at least partly, a mechanism for altered $5-\mathrm{HT}_{2 \mathrm{~A}} \mathrm{R}$ signaling in PACAP-deficient mice. Thus, the present study suggests that the endogenous PACAP in the brain modulates $5-\mathrm{HT}_{2 \mathrm{~A}} \mathrm{R}$ signaling, the dysfunction of which is implicated in the behavioral abnormalities. 